\title{
Racial and Ethnic Differences in ADHD Treatment Quality Among Medicaid-Enrolled Youth
}

Janet R. Cummings, PhD, Xu Ji, MSPH, Lindsay Allen, MA, Cathy Lally, MSPH, Benjamin G. Druss, MD, MPH

OBJECTIVES: We estimated racial/ethnic differences in attention-deficit/hyperactivity disorder (ADHD) care quality and treatment continuity among Medicaid-enrolled children. MEтHODS: Using Medicaid data from 9 states (2008 to 2011), we identified 172322 youth (age 6 to 12) initiating ADHD medication. Outcome measures included: (1) adequate follow-up care in the (a) initiation and (b) continuation and maintenance (C\&M) treatment phases; (2) combined treatment with medication and psychotherapy (versus medication alone); (3) medication discontinuation; and (4) treatment disengagement (ie, discontinued medication and received no psychotherapy). Logistic regressions controlled for confounding measures. RESULTS: Among those initiating medication, three-fifths received adequate follow-up care in the initiation and C\&M phases, and under two-fifths received combined treatment. Compared with whites, African American youth were less likely to receive adequate follow-up in either phase $(P<.05)$, whereas Hispanic youth were more likely to receive adequate follow-up in the $C \& M$ phase $(P<.001)$. African American and Hispanic youth were more likely than whites to receive combined treatment $(P<.05)$. Over three-fifths discontinued medication, and over four-tenths disengaged from treatment. Compared with whites, African American and Hispanic children were $22.4 \%$ and $16.7 \%$ points more likely to discontinue medication, and $13.1 \%$ and $9.4 \%$ points more likely to disengage from treatment, respectively $(P<.001)$.

concLusions: Care quality for Medicaid-enrolled youth initiating ADHD medication is poor, and racial/ethnic differences in these measures are mixed. The most important disparities occur in the higher rates of medication discontinuation among minorities, which translate into higher rates of treatment disengagement because most youth discontinuing medication receive no psychotherapy.

Department of Health Policy and Management, Rollins School of Public Health, Emory University, Atlanta, Georgia

Dr Cummings led the conceptualization and design of the study, interpreted the results, drafted the initial manuscript, and revised the manuscript; Ms Ji carried out the statistical analyses and assisted with interpretation of the results, and critically reviewed and revised the manuscript; Ms Allen and Ms Lally contributed to the statistical analyses, assisted with interpretation of the results, and critically reviewed and revised the manuscript; Dr Druss contributed to the conceptualization of the study design, assisted with the interpretation of the results, and critically reviewed and revised the manuscript; and all authors approved the final manuscript as submitted.

DOI: https://doi.org/10.1542/peds.2016-2444

Accepted for publication Mar 7, 2017
WHAT'S KNOWN ON THIS SUBJECT: African American and Hispanic youth have lower rates of attention-deficit/ hyperactivity disorder (ADHD) medication persistence and adherence than white children. Little is known about racial/ethnic differences in other dimensions of treatment and care quality among Medicaid-enrolled youth that initiate ADHD medication.

WHAT THIS STUDY ADDS: Using Medicaid data from 9 states and the largest sample to date, we examine racial/ethnic differences in ADHD care quality and treatment continuity. We examine outcomes not previously studied, including National Committee for Quality Assurance measures of adequate follow-up care.

To cite: Cummings JR, Ji X, Allen L, et al. Racial and Ethnic Differences in ADHD Treatment Quality Among Medicaid-Enrolled Youth. Pediatrics. 2017;139(6):e20162444 
Attention-deficit/hyperactivity disorder (ADHD) is 1 of the most common pediatric mental health (MH) disorders, ${ }^{1,2}$ and is associated with worse health, education, and employment outcomes. ${ }^{3-7}$ Medicaid is the largest payer of $\mathrm{MH}$ services in the United States, providing insurance to 27 million children. ${ }^{8}$ Given the size of this population and the consequences associated with ADHD, an improved understanding of ADHD treatment and care quality among diverse Medicaid-enrolled youth is essential for clinicians and policymakers.

Although effective treatments are available, previous research has revealed that African American and Hispanic youth are less likely to be diagnosed with ADHD than non-Hispanic white youth. ${ }^{9,10}$ For children who are diagnosed, ongoing treatment is critical because ADHD is a chronic $\mathrm{MH}$ disorder with symptoms that often continue into adolescence and adulthood. ${ }^{11,12}$ Pharmacotherapy (especially stimulant medication) is effective at reducing core ADHD symptoms, ${ }^{11,13}$ and it is received by more than nine-tenths of youth with an ADHDrelated health care visit. ${ }^{14}$ Yet, rates of ADHD medication adherence and persistence are low among Medicaidenrolled youth in general, ${ }^{15-18}$ and even lower among African American and Hispanic children than nonHispanic white children. ${ }^{18,19}$

Lower rates of ADHD medication persistence among minority youth compared with whites are most problematic if racial/ethnic minorities are also more likely to disengage from treatment entirely. Randomized trials have revealed that behavioral therapy is also effective at reducing ADHD symptoms. ${ }^{13,20-22}$ Little is known, however, about whether lower rates of medication persistence among African American and Hispanic youth (compared with white youth) are mitigated by an increased likelihood of using behavioral therapy services, or whether they lead to higher rates of disengagement from treatment altogether among racial/ethnic minorities.

More data are also needed to understand racial/ethnic differences in care quality among Medicaid enrolled-youth that continue medication. Because ADHD medication carries the risk of potentially intolerable side effects, ${ }^{11,23}$ timely follow-up visits with the provider are needed to monitor side effects, adjust dosing accordingly, or switch medications. ${ }^{24-26}$ Other research suggests that combining medication and behavioral therapy (versus medication alone) may yield better outcomes, ${ }^{20,27}$ especially among low-income youth. ${ }^{28,29}$ Consequently, clinical guidelines released by the American Academy of Pediatrics recommend combined medication and behavioral therapy as the preferred course of ADHD treatment versus either treatment alone. ${ }^{11}$ Yet, little is known about racial/ethnic differences in the receipt of timely follow-up visits or combined treatment among youth initiating ADHD medication.

To address these gaps in the literature, we used Medicaid claims data from 9 states and the largest sample to date to examine racial/ethnic differences in ADHD treatment continuity and care quality among children initiating ADHD medication. Our findings provide new information about the quality of ADHD treatment among a large, racially diverse sample of Medicaidenrolled youth, and can inform future quality improvement initiatives for this vulnerable population.

\section{METHODS}

\section{Data}

Data came from the 2008 to 2011

Medicaid Analytic eXtract (MAX)

Files for 9 states (AL, GA, KY, LA,
MO, NC, TN, TX, VA). The MAX data were merged with contextual-level measures from the 2011 Area Health Resource File and the 2008 National Survey of Mental Health Treatment Facilities. $^{30,31}$

\section{Analytic Samples}

Using criteria from the Healthcare Effectiveness Data and Information Set (HEDIS) ADHD performance measures, we identified 224320 children aged 6 to 12 years who initiated ADHD medication between January 1, 2008, and February 28, 2010,24,26 and had an ADHD diagnosis (International Classification of Diseases, Ninth Revision, Clinical Modification [ICD-9-CM] code: 314) on 2 distinct dates. ${ }^{14,19,32,33}$ The index date was the first reported prescription fill date for an ADHD medication after a 120-day exclusion period without ADHD medication (Fig 1). ${ }^{26,34}$ After identifying those that were continuously enrolled in Medicaid during the exclusion period and the 30-day medication initiation phase after the index date $(N=$ 174695), we also excluded those with an acute inpatient claim for MH or substance abuse, dual Medicare eligibility, multiple/inaccurate county codes, and/or missing information on control variables. This yielded our first sample of 172322 children who initiated ADHD medication.

Next, we derived a second sample of 157449 children who were also continuously enrolled in Medicaid throughout the continuation and maintenance (C\&M) phase of treatment and did not have any acute inpatient claims with an $\mathrm{MH}$ / substance abuse diagnosis. ${ }^{26}$ The C\&M phase is defined by HEDIS as the 270-day period after the 30-day medication initiation phase.

Lastly, we derived a third sample of children who were continuously enrolled and received continuous medication treatment during the C\&M phase $(N=62263)$, defined by HEDIS as having an ADHD 
prescription filled for at least 210 of the 300 days that span the initiation and C\&M phases. ${ }^{24,26}$

\section{Dependent Variables}

\section{Adequate Follow-up Care}

Two HEDIS measures establish criteria for adequate follow-up care after initiating and continuing ADHD medication. ${ }^{24,26}$ The first is an indicator for whether a child had at least 1 follow-up visit during the 30-day initiation phase with a health care provider that has prescribing authority (Fig 1). ${ }^{24,26}$ Because these MAX files lack sufficient providerlevel information on whether they had prescribing authority or not, we created an indicator for those who received at least 1 follow-up visit with any provider during the initiation phase (sample 1). Consequently, our indicator may provide a more inclusive estimate of the percentage of youth who received adequate follow-up care in the initiation phase than the HEDIS measure (and, conversely, a more conservative estimate of the percentage of youth who did not receive adequate follow-up care). For children who remained enrolled in Medicaid and on medication during the C\&M phase (sample 3), we derived the second HEDIS indicator that assesses whether an individual received at least 2 additional follow-up visits with any provider during the C\&M phase (Fig 1). ${ }^{24,26}$

\section{Combined Treatment}

Among youth who initiated and continued medication (sample 3), we created an indicator for those who received any psychotherapy visit (individual, family, or group) by using Current Procedural Terminology codes and a count measure for the number of psychotherapy visits.

\section{Treatment Disengagement}

For youth continuously enrolled for the entire study period (sample 2), we created an indicator for those who did

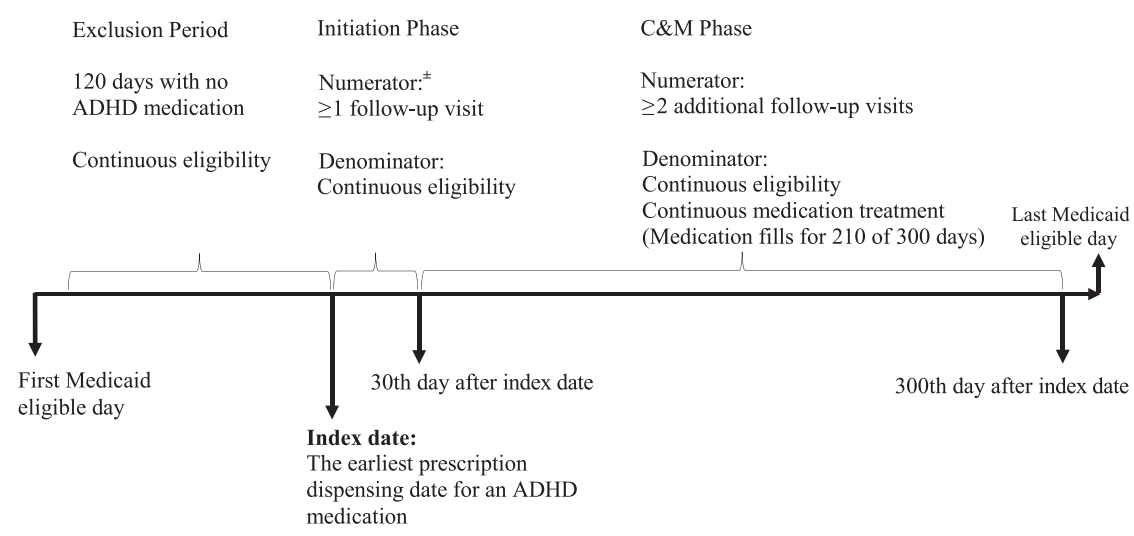

FIGURE 1

HEDIS measures of adequate follow-up care for children (age 6 to 12 years) initiating ADHD medication. \pm The numerator for this HEDIS measure assesses whether a child had $\geq 1$ follow-up visit with a health care provider that has prescribing authority. Because the available data did not have sufficient information about provider prescribing authority, an indicator was created for those with $\geq 1$ follow-up visit with any provider.

not meet the criteria for continuous medication treatment according to HEDIS specifications described above (ie, medication discontinuation). Then, we created an indicator to assess treatment disengagement for those who discontinued medication and did not receive any psychotherapy visit (including individual, family, or group psychotherapy). We also created alternative measures of treatment disengagement that used thresholds of 4 and 8 psychotherapy visits, because a single visit is not sufficient for families to engage in psychotherapy; these thresholds have been used in previous research of psychotherapy use among youth with ADHD. ${ }^{35}$

\section{Independent Variables}

\section{Race/Ethnicity}

Race/ethnicity was assessed with 5 mutually exclusive categories: nonHispanic white, non-Hispanic African American, Hispanic, non-Hispanic other race/ethnicity, and unknown race/ethnicity. Other race/ethnicity included those with multiple racial/ ethnic backgrounds and groups with sample sizes too small for separate analysis.

\section{Individual-Level Confounders}

Following Andersen's behavioral model of health care utilization, we controlled for individual-level predisposing, enabling, and needrelated characteristics. ${ }^{36}$ Measures of predisposing characteristics included age at the prescription index date (in years), and an indicator for female (versus male) sex. One enabling characteristic that may confound the association of interest is the type of health plan in which the child was enrolled. ${ }^{37,38}$ We used monthly measures in the MAX files to create a categorical measure of health plan type (see Table 1). Finally, we controlled for individual-level need-related characteristics with measures of Medicaid eligibility and comorbid conditions. Using the eligibility code from the most recent month in the study period, we created the following categories: (1) blind/disabled; (2) foster care; and (3) other basis of eligibility. We also created dichotomous indicators to control for mental and physical health comorbidities (see Table 1) for those with at least 2 outpatient and/or inpatient claims with the respective diagnosis codes (see Supplemental Table 5). 
TABLE 1 Sample Characteristics of Medicaid-Enrolled Youth (Age 6 to 12 y) That Initiated ADHD Medication, by Race/Ethnicity

\begin{tabular}{|c|c|c|c|c|c|c|}
\hline Sample Characteristics & $\begin{array}{c}\text { Total, } \\
N=172322\end{array}$ & White, $n=82515$ & $\begin{array}{c}\text { African } \\
\text { American, } \\
n=53304\end{array}$ & $\begin{array}{l}\text { Hispanic, } \\
n=24889\end{array}$ & Other, $n=1418$ & $\begin{array}{l}\text { Unknown, } n= \\
10196\end{array}$ \\
\hline \multicolumn{7}{|l|}{ Demographics } \\
\hline Age, mean (SD) & $8.0(1.8)$ & $7.9(1.8)$ & $8.1^{\star \star \star}(1.8)$ & $8.2^{\star \star \star}(1.8)$ & $8.1^{\star \star \star}(1.9)$ & $7.9(1.8)$ \\
\hline Girls, \% & 32.2 & 34.8 & $30.4^{\star \star \star}$ & $28.8^{\star \star \star}$ & $30.8^{\star \star}$ & $28.7^{\star \star \star}$ \\
\hline \multicolumn{7}{|l|}{ Plan type, \% } \\
\hline Fee-for-service only & 6.8 & 7.0 & $5.6^{\star \star \star}$ & $6.1^{\star \star \star}$ & 6.9 & $13.4^{\star \star \star}$ \\
\hline $\begin{array}{l}\text { Any behavioral health care carve-out } \\
\text { plan }\end{array}$ & 6.6 & 8.7 & $5.5^{\star \star \star}$ & $3.1^{\star \star \star}$ & $4.7^{\star \star \star}$ & $3.5^{\star \star \star}$ \\
\hline $\begin{array}{l}\text { Comprehensive managed care plan } \\
\text { (no carve-out) }\end{array}$ & 42.4 & 43.9 & $46.2^{\star \star \star}$ & $30.7^{\star \star \star}$ & $40.2^{\star \star}$ & $39.8^{* \star \star}$ \\
\hline $\begin{array}{l}\text { Primary care case management (no } \\
\text { carve-out) }\end{array}$ & 19.9 & 18.9 & $20.8^{\star \star \star}$ & $22.0^{\star \star \star}$ & 19.3 & $17.8^{\star \star}$ \\
\hline More than 1 type of plan & 24.4 & 21.5 & $22.0^{*}$ & $38.2^{\star \star \star}$ & $28.9^{\star \star \star}$ & $25.5^{\star \star \star}$ \\
\hline \multicolumn{7}{|l|}{ Eligibility type, \% } \\
\hline Blind/disabled & 9.7 & 3.2 & $9.9^{\star \star \star}$ & $9.8^{\star \star \star}$ & $7.7^{\star \star \star}$ & $61.7^{\star \star \star}$ \\
\hline Foster care & 6.6 & 6.5 & $7.3^{\star \star \star}$ & $7.1^{\star \star \star}$ & 6.2 & $2.5^{\star \star \star}$ \\
\hline Other eligibility type ${ }^{a}$ & 83.7 & 90.3 & $82.8^{* \star \star}$ & $83.1^{\star \star k *}$ & $86.1^{\star \star \star}$ & $35.8^{* \star \star}$ \\
\hline \multicolumn{7}{|l|}{ Physical health comorbidity, \% } \\
\hline Asthma & 17.6 & 15.0 & $20.3^{\star \star \star}$ & $18.5^{\star \star \star}$ & $18.8^{\star \star \star}$ & $21.3^{\star \star \star}$ \\
\hline Any other chronic condition ${ }^{b}$ & 3.7 & 3.3 & $2.9^{\star \star \star}$ & $4.3^{* \star \star}$ & 3.9 & $9.4^{\star \star \star}$ \\
\hline \multicolumn{7}{|l|}{ MH comorbidity, \% } \\
\hline Depressive disorder & 6.8 & 6.3 & $7.1^{\star \star \star}$ & $8.4^{\star \star \star}$ & 5.6 & 5.9 \\
\hline $\begin{array}{l}\text { Conduct disorder/oppositional } \\
\text { defiant disorder }\end{array}$ & 21.7 & 19.0 & $26.0^{* \star \star}$ & $20.7^{\star \star \star \star}$ & $27.6^{\star \star \star}$ & $22.1^{\star \star \star}$ \\
\hline Anxiety disorder & 5.9 & 6.6 & $4.6^{\star \star \star}$ & 6.4 & $4.4^{* \star \star}$ & 6.4 \\
\hline Bipolar disorder & 8.2 & 8.0 & 7.9 & $8.9^{\star \star \star}$ & 7.4 & $10.9^{\star \star \star}$ \\
\hline $\begin{array}{l}\text { Schizophrenia/other psychotic } \\
\text { disorder }\end{array}$ & 0.9 & 0.6 & $1.3^{\star \star \star}$ & $1.1^{\star \star \star}$ & 0.9 & $1.6^{\star \star \star}$ \\
\hline Other $\mathrm{MH}$ disorder & 33.5 & 33.2 & $30.0^{* \star \star}$ & $37.0^{* \star *}$ & $38.6^{* \star \star}$ & $44.1^{\star \star \star}$ \\
\hline \multicolumn{7}{|l|}{ County-level characteristics, mean (SD) } \\
\hline Percentage living in urban area & $66.1(29.6)$ & $54.8(29.3)$ & $74.1^{\star \star \star}(27.1)$ & $85.1^{\star \star \star}(19.0)$ & $62.1^{\star \star \star}(29.8)$ & $70.5^{\star \star \star}(28.4)$ \\
\hline Percentage living in poverty & $17.0(6.0)$ & $15.9(5.0)$ & $17.0^{\star \star \star}(5.2)$ & $20.7^{\star \star \star}(8.4)$ & $18.3^{\star \star \star}(7.8)$ & $17.1^{\star \star \star}(6.1)$ \\
\hline Outpatient MH facilities per 100K & $1.3(2.0)$ & $1.6(2.2)$ & $1.2^{\star \star \star}(1.8)$ & $0.6^{\star \star \star}(1.4)$ & $1.0^{\star \star \star}(1.4)$ & $1.2^{\star \star \star}(1.9)$ \\
\hline Community health centers per $100 \mathrm{~K}$ & $3.7(6.7)$ & $4.4(7.6)$ & $2.9^{\star \star \star}(5.5)$ & $3.2^{\star \star \star}(5.9)$ & $4.8^{\star}(6.0)$ & $3.0^{\star \star \star}(5.6)$ \\
\hline Primary care physicians per $100 \mathrm{~K}$ & $59.8(27.6)$ & $56.3(28.6)$ & $67.6^{\star \star \star}(27.9)$ & $54.6^{\star \star \star}(19.8)$ & $59.7^{\star \star \star}(29.1)$ & $60.8^{\star \star \star}(25.7)$ \\
\hline Psychologists per 100K & $15.8(16.8)$ & $13.6(15.9)$ & $20.4^{\star \star \star}(18.7)$ & $12.6^{\star \star \star}(12.9)$ & $15.4^{\star \star \star}(20.2)$ & $17.1^{\star \star \star}(16.8)$ \\
\hline
\end{tabular}

a "Other eligibility type" included children eligible for Medicaid on the basis of household income, classification as "medically needy," and/or other criteria specified in each state's Section 1115 waiver.

b "Other chronic conditions" included cerebral palsy, cystic fibrosis, diabetes, spina bifida, seizure disorder, congenital heart disease, sickle cell disease, and malignant neoplasms.

${ }^{*} P<.05$.

${ }^{* *} P<.01$.

${ }^{\star * *} P<.001$.

\section{County-Level Confounders}

County-level socioeconomic status was assessed with the percentage of residents living in poverty in 2008 . Urbanicity was measured by the percentage of county residents living in an urban area (2000), as defined by the US Census Bureau. ${ }^{39}$

We included 4 county-level measures of MH care resources per 100000 persons: (1) community health centers (ie, federally qualified health centers and rural health clinics) in 2008 , (2) primary care physicians in
2010, (3) outpatient MH facilities that served youth and accepted Medicaid in 2008; and (4) psychologists in 2009.

\section{Analysis}

We conducted bivariate analyses by using Wald tests. ${ }^{40} \mathrm{Next}$, we drew on the Institute of Medicine's definition of a health care disparity and estimated logistic and zerotruncated negative binomial regression models, ${ }^{41}$ controlling for individual-level and county-level confounding measures. ${ }^{36,42}$ All regressions included state indicators, and SEs were clustered at the county level. Marginal effects (MEs) for each racial/ethnic minority group (relative to white children) were calculated at the observed values of other predictor variables in the models; the ME can be interpreted as the percentage point difference in the probability that an outcome occurs in each minority group, compared with white children. Regression results for racial/ethnic differences in these outcome measures are presented below, and regression results for all 


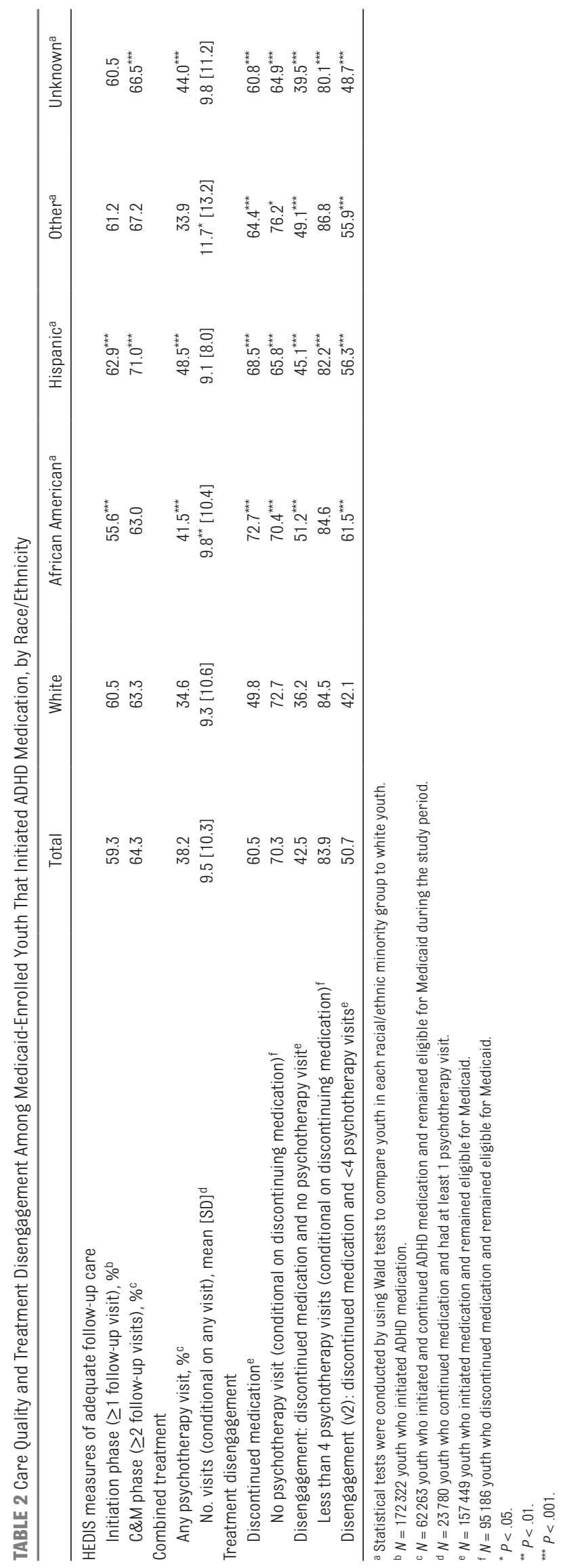

model covariates are available as Supplemental Tables 6 and 7.

\section{RESULTS}

\section{Quality of Care and Treatment Disengagement Among Youth Initiating ADHD Medication}

Of those who initiated medication, less than three-fifths (59.3\%) visited a provider within 30 days (Table 2 ). of those who initiated and continued medication, three-fifths (64.3\%) received at least 2 additional visits with a provider and less than fourtenths $(38.2 \%)$ received combined treatment with any psychotherapy visit.

Three-fifths who initiated medication did not fill ADHD prescriptions for enough days (ie, 210 of 300 days) to be classified as receiving continuous medication according to the HEDIS measure. Of those who discontinued medication, more than seven-tenths did not receive any psychotherapy visit and more than four-tenths disengaged from treatment.

\section{Racial/Ethnic Differences in Quality of Care and Treatment Disengagement}

\section{Adequate Follow-up Visits}

Nearly half of the sample was nonHispanic white (47.9\%), nearly one-third was African American (30.9\%), and more than one-tenth (14.4\%) was Hispanic (Table 1). The percentage that received any follow-up visit in the initiation phase was lower among African American versus white children in the bivariate (55.6\% vs $60.5 \%, P<.001$; Table 2 ) and adjusted comparison (ME $=-5.7 \%$ points, $P<.001$;

Table 3). In addition, African American children were less likely than white children to receive adequate follow-up care in the C\&M phase in the adjusted comparison (ME $=-2.2 \%$ points, $P<.01)$.

Unlike the finding for African American children, Hispanic children 


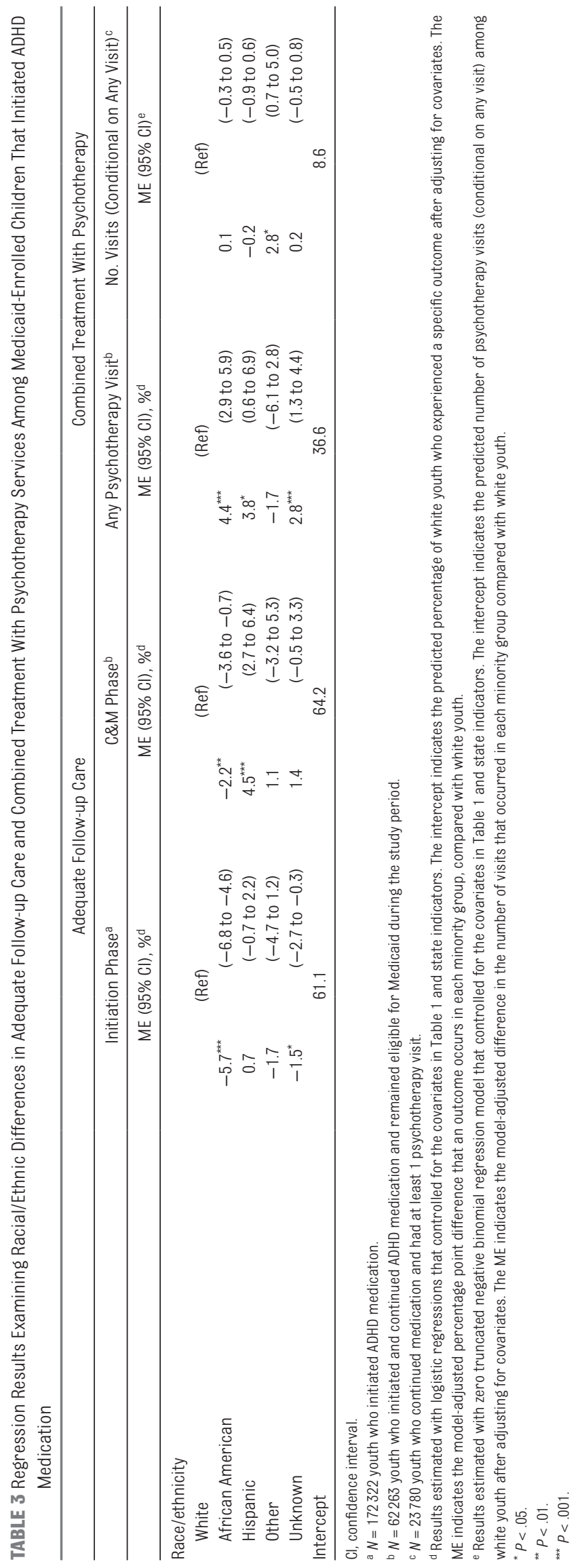

were more likely than white children to receive adequate follow-up care in the initiation phase $(62.9 \%$ vs $60.5 \%$, $P<.001)$ and in the C\&M phase (71.0\% vs $63.3 \%, P<.001)$ in the bivariate comparisons (Table 2). The higher rate of adequate follow-up care in the C\&M phase among Hispanic versus white children was attenuated but remained significant ( $\mathrm{ME}=4.5 \%$ points, $P<.001$ ) in the adjusted comparison (Table 3 ).

\section{Combined Treatment}

Among those who continued medication treatment, African American and Hispanic youth were significantly more likely than white youth to receive any psychotherapy visit in the bivariate (Table 2) and multivariate (Table 3) comparisons. However, there were no significant differences in the number of psychotherapy visits received among African American and Hispanic youth (versus white youth) with at least 1 visit.

\section{Treatment Disengagement}

Results from the bivariate (Table 2) and multivariate analyses (Table 4) reveal large racial/ethnic differences in medication discontinuation and treatment disengagement. More specifically, the MEs indicate that the adjusted rate of discontinuing medication was $22.4 \%$ points higher $(P<.001)$ among African American versus white youth and $16.7 \%$ points higher $(P<.001)$ among Hispanic versus white youth. Although African American $(P<.001)$ youth were more likely than white youth to receive at least 1 psychotherapy visit among those who discontinued medication in the bivariate and adjusted comparison, these higher rates of any psychotherapy use did not compensate for the even higher rates of medication discontinuation. Thus, the adjusted rates of treatment disengagement among African American (ME = 13.1\% points, $P<.001)$ and Hispanic (ME = $9.4 \%$ points, $P<.001$ ) youth were 
significantly higher than among white youth.

Among those who discontinued medication, there were no racial/ethnic differences in the likelihood of receiving at least 4 psychotherapy visits. Thus, the racial/ethnic differences in the second specification of treatment disengagement were more pronounced than the first. This pattern of findings was similar when examining a third specification of disengagement that used a threshold of 8 psychotherapy visits (not shown).

\section{Supplemental Analyses}

We estimated additional models that excluded the county-level measures of the health and $\mathrm{MH}$ care infrastructure. The racial/ ethnic differences in each outcome measure were qualitatively similar in magnitude and significance after excluding these measures from the model.

\section{DISCUSSION}

Overall, the quality of care for Medicaid-enrolled youth initiating ADHD medication is poor and racial/ ethnic differences in these measures were mixed. The most important differences occur in the much higher rates of medication discontinuation and treatment disengagement among minority youth compared with white youth.

Consistent with previous studies, ${ }^{18,19}$ there were considerable racial/ ethnic differences in medication discontinuation. Higher rates of medication discontinuation among minority youth could be due to differences in cultural health beliefs and/or concerns about ADHD medication treatment. African American parents are less likely than white parents to conceptualize ADHD as a medical condition requiring treatment, ${ }^{43,44}$ and may be less willing to 
administer psychotropic medication to a child due to beliefs about medication efficacy and side effects. ${ }^{45}$ ADHD medication is associated with an increased risk of adverse effects (eg, sleep problems and appetite suppression), ${ }^{11,23}$ and a substantial proportion of treatment discontinuation is due to these adverse effects. ${ }^{46}$ More research is needed to understand whether higher rates of medication discontinuation among minority youth are driven by racial/ethnic differences in child experiences with side effects, parent perspectives of these side effects, or both.

A more complex picture emerges for racial/ethnic differences in ADHD treatment utilization when examining the receipt of psychotherapy services and treatment disengagement. African American and Hispanic youth were more likely than white youth to receive any psychotherapy among the sample that continued medication, and African American youth were more likely than white youth to receive any psychotherapy among the sample that discontinued medication. These findings are in line with research indicating that racial/ethnic minority parents may prefer psychosocial treatments over medication for ADHD. ${ }^{47,48}$ It is important to note, however, that psychotherapy as measured in our data (and other administrative data sets due to the lack of specificity in the Current Procedural Terminology codes) can include behavioral therapy, an evidence-based treatment of ADHD, ${ }^{11,49}$ and other forms of psychotherapy that may not be evidence-based approaches for ADHD. Thus, the percentage that received any evidence-based psychotherapeutic treatment of ADHD would likely be smaller than that assessed by the available measure. In addition, the slightly higher rate of any psychotherapy use among minority youth did not compensate for the much higher rates of medication discontinuation, which translated into significantly higher overall rates of treatment disengagement for African American and Hispanic youth.

There are 2 possible approaches to improve these disparities in ADHD treatment disengagement among racial/ethnic minorities. On the one hand, quality improvement efforts to address medication continuity could focus on improving medication persistence among racial/ethnic minorities. An alternative approach would entail recognition that minority families may prefer psychosocial treatments to be received concurrently with or in lieu of medication. Thus, quality improvement efforts may focus on improving the accessibility of behavioral therapy as a strategy to reduce disparities in ADHD treatment disengagement.

Regarding the receipt of adequate follow-up care, three-fifths of those initiating medication received adequate follow-up care as assessed by the National Committee for Quality Assurance. This rate is higher than the rate that was reported among commercially insured youth with ADHD, of whom less than half received adequate follow-up care in the initiation phase $(49.8 \%)$ and the C\&M phase $(45.8 \%)$ of treatment. ${ }^{50} \mathrm{We}$ also found that racial/ethnic differences in these measures were mixed; African American youth were less likely to receive adequate follow-up care in both phases of treatment, whereas Hispanic youth were more likely to receive adequate follow-up visits compared with white youth in the C\&M phase. Nevertheless, our findings raise 2 important issues for researchers who seek to assess racial/ethnic differences in ADHD care quality using the National Committee for Quality Assurance HEDIS measures. First, the HEDIS measure assessing adequate follow-up visits in the C\&M phase does not provide information about care quality for the majority of youth who initiate ADHD medication, because most youth do not continue medication. Second, the most striking racial/ethnic differences in ADHD treatment among youth who initiate medication are not captured by either HEDIS measure of adequate follow-up care; rather, the most important differences occur in the rate of medication discontinuation and treatment disengagement.

Several study limitations are noted. As with any analysis using administrative data, coding errors may introduce measurement error. ${ }^{51}$ Claims-based measures also have a limited ability to identify clinical need for treatment, or the reasons for treatment discontinuation. In addition, the data do not provide information about ADHD treatment and quality among youth for whom Medicaid coverage discontinued, an important topic for future investigation. Furthermore, these analyses were conducted by using data from states predominantly in the southeast region, and the findings may not generalize to other regions of the country. Nonetheless, Medicaid-enrolled youth in these states constitute an important sample for study because nearly four-tenths (38.1\%) of African American youth and more than one-fourth $(26.7 \%)$ of Hispanic youth in the US live in 1 of these 9 states. ${ }^{52-54}$

Lastly, the age of the data poses a limitation. MAX files have a lag time of several years and 2011 was the most recent year available at the time the data use agreement was obtained. Although the HEDIS measures had been published by the beginning of the study period, ${ }^{55}$ the American Academy of Pediatrics guidelines (recommending combined treatment 
with medication and behavioral therapy as the "preferred treatment" for this age group) were published in 2011. ${ }^{11}$ Importantly, however, many of the key studies on which these guidelines were based were published before our study time frame. ${ }^{20,27,56,57}$ Furthermore, the data lag would only bias our findings if changes in the rate of combined treatment after the publication of the guidelines differed across racial/ ethnic groups. As newer data become available, future studies should assess if these outcome measures change over time.
Notwithstanding limitations, this study provides the most comprehensive examination of racial/ethnic differences in ADHD treatment continuity and care quality to date among Medicaid-enrolled youth. Overall, our findings indicate that the quality of care among youth initiating ADHD medication is poor. Moreover, the most concerning racial/ethnic disparities in care occur in the rate of treatment disengagement. More work is needed to understand the causes for these gaps in quality, which will inform future strategies to address them.

\section{ABBREVIATIONS}

ADHD: attention-deficit/ hyperactivity disorder

C\&M: continuation and maintenance

HEDIS: Healthcare Effectiveness Data and Information Set

ICD-9-CM: International Classification of Diseases, Ninth Revision, Clinical Modification

MAX: Medicaid Analytic eXtract ME: marginal effect

MH: mental health

Address correspondence to Janet R. Cummings, PhD, Department of Health Policy and Management, Emory University, Rollins School of Public Health, 1518 Clifton Rd NE, Room 650, Atlanta, GA 30322. E-mail: jrcummi@emory.edu PEDIATRICS (ISSN Numbers: Print, 0031-4005; Online, 1098-4275). Copyright (C) 2017 by the American Academy of Pediatrics

FINANCIAL DISCLOSURE: The authors have indicated they have no financial relationships relevant to this article to disclose.

FUNDING: Supported by the National Institute of Mental Health (K01MH095823). The content is solely the responsibility of the authors and does not necessarily represent the official views of the National Institutes of Health. Funded by the National Institutes of Health (NIH).

POTENTIAL CONFLICT OF INTEREST: The authors have indicated they have no potential conflicts of interest to disclose.

\section{REFERENCES}

1. Merikangas KR, He J-P, Brody D, Fisher PW, Bourdon K, Koretz DS. Prevalence and treatment of mental disorders among US children in the 2001-2004 NHANES. Pediatrics. 2010;125(1):75-81

2. Merikangas KR, He JP, Burstein M, et al. Lifetime prevalence of mental disorders in U.S. adolescents: results from the National comorbidity survey replication-adolescent supplement (NCS-A). J Am Acad Child Adolesc Psychiatry. 2010;49(10):980-989

3. Currie J, Stabile M. Child mental health and human capital accumulation: the case of ADHD. J Health Econ. 2006;25(6):1094-1118

4. Barbaresi WJ, Katusic SK, Colligan RC, Weaver AL, Jacobsen SJ. Long-term school outcomes for children with attention-deficit/hyperactivity disorder a population-based perspective. J Dev Behav Pediatr. 2007;28(4):265-273

5. Klassen AF, Miller A, Fine S. Healthrelated quality of life in children and adolescents who have a diagnosis of attention-deficit/hyperactivity disorder.
Pediatrics. 2004;114(5). Available at: www.pediatrics.org/cgi/content/full/ 114/5/e541

6. Barkley RA. Major life activity and health outcomes associated with attention-deficit/hyperactivity disorder. J Clin Psychiatry. 2002;63 (suppl 12):10-15

7. Biederman J, Monuteaux MC, Doyle AE, et al. Impact of executive function deficits and attentiondeficit/hyperactivity disorder (ADHD) on academic outcomes in children. J Consult Clin Psychol. 2004;72(5):757-766

8. Centers for Medicare \& Medicaid Services. Behavioral health services. Available at: https://www.medicaid.gov/ medicaid-chip-program-information/bytopics/benefits/mental-health-services. html. Accessed November 1, 2016

9. Schneider H, Eisenberg D. Who receives a diagnosis of attention-deficit/ hyperactivity disorder in the United States elementary school population? Pediatrics. 2006;117(4). Available at: www.pediatrics.org/cgi/content/full/ 117/4/e601

10. Miller TW, Nigg JT, Miller RL. Attention deficit hyperactivity disorder in African American children: what can be concluded from the past ten years? Clin Psychol Rev. 2009;29(1):77-86

11. Wolraich M, Brown L, Brown RT, et al; Subcommittee on Attention-Deficit/ Hyperactivity Disorder; Steering Committee on Quality Improvement and Management. ADHD: clinical practice guideline for the diagnosis, evaluation, and treatment of attentiondeficit/hyperactivity disorder in children and adolescents. Pediatrics. 2011;128(5):1007-1022

12. Ingram S, Hechtman L, Morgenstern G. Outcome issues in ADHD: adolescent and adult long-term outcome. Ment Retard Dev Disabil Res Rev. 1999;5(3):243-250

13. MTA Cooperative Group. National Institute of Mental Health multimodal treatment study of ADHD follow-up: 24-month outcomes of treatment 
strategies for attention-deficit/ hyperactivity disorder. Pediatrics. 2004;113(4):754-761

14. Olfson M, Gameroff MJ, Marcus SC, Jensen PS. National trends in the treatment of attention deficit hyperactivity disorder. Am J Psychiatry. 2003;160(6):1071-1077

15. Winterstein AG, Gerhard T, Shuster $J$, et al. Utilization of pharmacologic treatment in youths with attention deficit/hyperactivity disorder in Medicaid database. Ann Pharmacother. 2008;42(1):24-31

16. Palli SR, Kamble PS, Chen H, Aparasu RR. Persistence of stimulants in children and adolescents with attention-deficit/hyperactivity disorder. $J$ Child Adolesc Psychopharmacol. 2012;22(2):139-148

17. Zima BT, Bussing R, Tang L, et al. Quality of care for childhood attentiondeficit/hyperactivity disorder in a managed care Medicaid program. $\checkmark$ Am Acad Child Adolesc Psychiatry. 2010;49(12):1225-1237, 1237. e1-1237.e11

18. Saloner B, Fullerton C, McGuire T. The impact of long-acting medications on attention-deficit/hyperactivity disorder treatment disparities. J Child Adolesc Psychopharmacol. 2013;23(6): 401-409

19. Marcus SC, Wan GJ, Kemner JE, Olfson M. Continuity of methylphenidate treatment for attention-deficit/ hyperactivity disorder. Arch Pediatr Adolesc Med. 2005;159(6):572-578

20. Jensen PS, Hinshaw SP, Swanson $\mathrm{JM}$, et al. Findings from the NIMH multimodal treatment study of ADHD (MTA): implications and applications for primary care providers. J Dev Behav Pediatr. 2001;22(1):60-73

21. Pelham WE Jr, Fabiano GA. Evidencebased psychosocial treatments for attention-deficit/hyperactivity disorder. J Clin Child Adolesc Psychol. 2008;37(1):184-214

22. The MTA Cooperative Group. Multimodal Treatment Study of Children with ADHD. A 14-month randomized clinical trial of treatment strategies for attention-deficit/ hyperactivity disorder. Arch Gen Psychiatry. 1999;56(12):1073-1086
23. Storebø 0J, Simonsen E, Gluud C. Methylphenidate for attentiondeficit/hyperactivity disorder in children and adolescents. JAMA. 2016;315(18):2009-2010

24. National Committee for Quality Assurance. Follow-up care for children prescribed ADHD medication (ADD). Available at: www.ncqa.org/portals/ 0/Follow-Up\%20Care\%20for\%20 Children\%20Prescribed\%20ADHD\%20 Medication.pdf. Accessed November 1, 2016

25. National Committee on Quality Assurance. HEDIS \& performance measurement. Available at: www.ncqa. org/HEDISQualityMeasurement.aspx. Accessed November 1, 2016

26. National Committee on Quality Assurance. HEDIS archives. Available at: www.ncqa.org/hedis-qualitymeasurement/hedis-measures/hedisarchives. Accessed November 1, 2016

27. Pelham WE, Gnagy EM. Psychosocial and combined treatments for ADHD. Ment Retard Dev Disabil Res Rev. 1999;5(3):225-236

28. MTA Cooperative Group. Moderators and mediators of treatment response for children with attention-deficit/ hyperactivity disorder: the multimodal treatment study of children with attention-deficit/hyperactivity disorder. Arch Gen Psychiatry. 1999;56(12):1088-1096

29. Murray DW, Arnold LE, Swanson J, et al. A clinical review of outcomes of the multimodal treatment study of children with attention-deficit/ hyperactivity disorder (MTA). Curr Psychiatry Rep. 2008;10(5):424-431

30. Area Health Resource Files. Rockville, MD: US Department of Health and Human Services, Health Resources and Services Administration, Bureau of Health Professions; 2011-2012

31. National Survey of Mental Health Treatment Facilities. Rockville, MD: Center for Mental Health Services, Substance Abuse and Mental Health Services Administration; 2008

32. Fullerton CA, Epstein AM, Frank RG, Normand S-LT, Fu CX, McGuire TG. Medication use and spending trends among children with ADHD in Florida's
Medicaid program, 1996-2005.

Psychiatr Serv. 2012;63(2):115-121

33. Chen C-Y, Gerhard T, Winterstein AG. Determinants of initial pharmacological treatment for youths with attention-deficit/ hyperactivity disorder. J Child Adolesc Psychopharmacol. 2009;19(2):187-195

34. National Committee for Quality Assurance. HEDIS 2013 final NDC lists. Available at: www.ncqa.org/hedisquality-measurement/hedis-measures/ hedis-2013/hedis-2013-final-ndc-lists. Accessed November 1, 2016

35. Gellad WF, Stein BD, Ruder T, et al. Geographic variation in receipt of psychotherapy in children receiving attention-deficit/hyperactivity disorder medications. JAMA Pediatr. 2014;168(11):1074-1076

36. Andersen RM. Revisiting the behavioral model and access to medical care: does it matter? J Health Soc Behav. 1995;36(1):1-10

37. Simon GE, Von Korff M, Rutter CM, Peterson DA. Treatment process and outcomes for managed care patients receiving new antidepressant prescriptions from psychiatrists and primary care physicians. Arch Gen Psychiatry. 2001;58(4):395-401

38. Wells KB, Sherbourne C, Schoenbaum $M$, et al. Impact of disseminating quality improvement programs for depression in managed primary care a randomized controlled trial. JAMA. 2000;283 (2) :212-220

39. US Census Bureau. Census 2000 geographic terms and concepts. Available at: https://www2.census gov/geo/pdfs/reference/glossry2.pdf. Accessed November 1, 2016

40. Korn EL, Graubard BI. Simultaneous testing of regression coefficients with complex survey data: use of Bonferroni t statistics. Am Stat. 1990;44(4):270-276

41. Smedley BD, Stith AY, Nelson AR, eds. Unequal Treatment: Confronting Racial and Ethnic Disparities in Health Care. Washington, DC: Institute of Medicine; 2003

42. Long JS, Freese J. Count outcomes: regression models for counts. In: Regression Models for Categorical 
and Limited Dependent Variables.

Thousand Oaks, CA: Sage; 1997:217-251

43. Bussing R, Schoenberg NE, Perwien AR. Knowledge and information about ADHD: evidence of cultural differences among African-American and white parents. Soc Sci Med. 1998;46(7):919-928

44. Bussing R, Zima BT, Gary FA, Garvan CW. Barriers to detection, help-seeking, and service use for children with ADHD symptoms. J Behav Health Serv Res. 2003;30(2):176-189

45. Schnittker J. Misgivings of medicine? African Americans' skepticism of psychiatric medication. J Health Soc Behav. 2003:44(4):506-524

46. Charach A, Fernandez R. Enhancing ADHD medication adherence: challenges and opportunities. Curr Psychiatry Rep. 2013;15(7):371

47. Dosreis S, Zito JM, Safer DJ, Soeken KL, Mitchell JW Jr, Ellwood LC. Parental perceptions and satisfaction with stimulant medication for attentiondeficit hyperactivity disorder. J Dev Behav Pediatr. 2003;24(3):155-162

48. Pham AV, Carlson JS, Kosciulek JF. Ethnic differences in parental beliefs of attention-deficit/hyperactivity disorder and treatment. J Atten Disord. 2010;13(6):584-591
49. Chronis AM, Jones HA, Raggi VL. Evidence-based psychosocial treatments for children and adolescents with attention-deficit/ hyperactivity disorder. Clin Psychol Rev. 2006;26(4):486-502

50. Bussing R, Narwaney KJ, Winterstein $A G$, et al. Pharmacotherapy for incident attention-deficit/hyperactivity disorder: practice patterns and quality metrics. Curr Med Res Opin. 2014;30(8):1687-1699

51. O'Malley KJ, Cook KF, Price MD, Wildes $\mathrm{KR}$, Hurdle JF, Ashton CM. Measuring diagnoses: ICD code accuracy. Health Serv Res. 2005;40(5 pt 2):1620-1639

52. US Census Bureau, Population Division. Annual state resident population estimates for 6 race groups (5 race alone groups and two or more races) by age, sex, and Hispanic origin: April 1, 2010 to July 1, 2012. 2012 population estimates. Available at: www.census. gov/popest/data/state/asrh/2012/ SC-EST2012-ALLDATA6.html. Accessed December 11, 2016

53. US Census Bureau, Population Division. Annual estimates of the resident population by sex, age, race, and Hispanic origin for the United States and States: April 1, 2010 to July 1, 2012, 2012 population estimates. Table PEPASR6H. Available at: https://factfinder.census.gov/ faces/tableservices/jsf/pages/ productview.xhtml?pid=PEP_2012_ PEPASR6H\#x26prodType=table. Accessed June 2013

54. Children's Defense Fund. The State of America's Children. Washington, DC: Children's Defense Fund; 2014. Available at: www.childrensdefense. org/library/state-of-americas-children/ 2014-soac.pdf?utm_source=2014SOAC-PDF\&utm_medium=link\&utm_ campaign=2014-SOAC. Accessed December 10, 2016

55. Manos MJ, Tom-Revzon C, Bukstein OG, Crismon ML. Changes and challenges: managing ADHD in a fast-paced world. J Manag Care Pharm. 2007;13 (9 suppl B) :S2-S13, quiz S14-S16

56. Pelham WE Jr, Wheeler T, Chronis A. Empirically supported psychosocial treatments for attention deficit hyperactivity disorder. J Clin Child Psychol. 1998;27(2):190-205

57. Sonuga-Barke EJ, Daley D, Thompson M, Laver-Bradbury C, Weeks A. Parent-based therapies for preschool attention-deficit/hyperactivity disorder: a randomized, controlled trial with a community sample. J Am Acad Child Adolesc Psychiatry. 2001;40(4):402-408 